\title{
Changing to a vegetarian diet reduces the body creatine pool in omnivorous women, but appears not to affect carnitine and carnosine homeostasis: a randomised trial
}

\author{
Laura Blancquaert ${ }^{1}$, Audrey Baguet ${ }^{1}$, Tine Bex ${ }^{1}$, Anneke Volkaert ${ }^{1}$, Inge Everaert ${ }^{1}$, Joris Delanghe ${ }^{2}$, \\ Mirko Petrovic ${ }^{3}$, Chris Vervaet ${ }^{4}$, Stefaan De Henauw ${ }^{5}$, Dumitru Constantin-Teodosiu ${ }^{6}$, Paul Greenhaff ${ }^{6}$ \\ and Wim Derave ${ }^{1 *}$ \\ ${ }^{1}$ Department of Movement and Sports Sciences, Ghent University, 9000 Ghent, Belgium \\ ${ }^{2}$ Department of Clinical Chemistry, Ghent University Hospital, 9000 Ghent, Belgium \\ ${ }^{3}$ Department of Internal Medicine, Ghent University, 9000 Ghent, Belgium \\ ${ }^{4}$ Laboratory of Pharmaceutical Technology, Ghent University, 9000 Ghent, Belgium \\ ${ }^{5}$ Department of Public Health, Ghent University, 9000 Ghent, Belgium \\ ${ }^{6}$ School of Life Sciences, Medical Research Council (MRC)/Arthritis Research UK Centre for Musculoskeletal Ageing Research, \\ Queen's Medical Centre, University of Nottingham Medical School, Nottingham NG7 2UH, UK
}

(Submitted 22 September 2017 - Final revision received 22 December 2017 - Accepted 7 January 2018)

\section{Abstract}

Balanced vegetarian diets are popular, although they are nearly absent in creatine and carnosine and contain considerably less carnitine than non-vegetarian diets. Few longitudinal intervention studies investigating the effect of a vegetarian diet on the availability of these compounds currently exist. We aimed to investigate the effect of transiently switching omnivores onto a vegetarian diet for 6 months on muscle and plasma creatine, carnitine and carnosine homeostasis. In a 6-month intervention, forty omnivorous women were ascribed to three groups: continued omnivorous diet (control, $n$ 10), vegetarian diet without supplementation $(\mathrm{Veg}+\mathrm{Pla}, n 15)$ and vegetarian diet combined with daily $\beta$-alanine $(0.8-0.4 \mathrm{~g} / \mathrm{d})$ and creatine supplementation ( $1 \mathrm{~g}$ creatine monohydrate/d) (Veg + Suppl, $n$ 15). Before (0 months; 0M), after 3 months ( $3 \mathrm{M})$ and 6 months $(6 \mathrm{M})$, a fasted venous blood sample and 24-h urine was collected, and muscle carnosine content was determined by proton magnetic resonance spectroscopy $\left({ }^{1} \mathrm{H}-\mathrm{MRS}\right)$. Muscle biopsies were obtained at $0 \mathrm{M}$ and $3 \mathrm{M}$. Plasma creatine and muscle total creatine content declined from $0 \mathrm{M}$ to $3 \mathrm{M}$ in $\mathrm{Veg}+\mathrm{Pla}(P=0.013$ and $P=0 \cdot 009$, respectively), whereas plasma creatine increased from $0 \mathrm{M}$ in Veg + Suppl $(P=0.004)$. None of the carnitine-related compounds in plasma or muscle showed a significant time $\times$ group interaction effect. ${ }^{1} \mathrm{H}-\mathrm{MRS}-$ determined muscle carnosine content was unchanged over $6 \mathrm{M}$ in control and Veg $+\mathrm{Pla}$, but increased in Veg + Suppl in soleus $(P<0 \cdot 001)$ and gastrocnemius $(P=0 \cdot 001)$ muscle. To conclude, the body creatine pool declined over a 3-month vegetarian diet in omnivorous women, which was ameliorated when accompanied by low-dose dietary creatine supplementation. Carnitine and carnosine homeostasis was unaffected by a 3- or 6-month vegetarian diet, respectively.

Key words: Lacto-ovo-vegetarians: $\beta$-Alanine: Homeostasis: Supplements

Vegetarian dietary patterns are becoming increasingly popular for various ecological, ethical or health-related reasons. A high consumption of red and processed meat has been consistently demonstrated to elevate mortality risk from certain cancers ${ }^{(1)}$ and $\mathrm{CVD}^{(2,3)}$. Yet, it is unclear whether the reduced mortality risk in lacto-ovo vegetarians, found in some studies, is related to the omission of meat and fish, or rather to more prevalent diet-unrelated health-conscious behaviour. A balanced lactoovo-vegetarian diet differs in nutrient intake from an omnivorous diet, for example by increased intake of fibre, $\mathrm{Mg}$ and antioxidants, but lower intake of $n-3$ (omega-3) fatty acids and vitamin $\mathrm{B}_{12}{ }^{(4)}$, all of which is reasonably well documented in the scientific literature. However, the impact of reduced to near absent intake of carnitine, carnosine and creatine in a vegetarian diet is less well established and could be relevant in relation to muscle function, exercise capacity and sports performance.

Carnitine, carnosine and creatine are preferentially or solely found in tissues of animals, with highest concentrations in skeletal muscle tissue (hence the names, derived from latin carnis and greek kreas, flesh). They neither qualify as

Abbreviations: 0M, 0 months (baseline); 3M, 3 months; 6M, 6 months; TTE, time to exhaustion; Veg + Pla, vegetarian diet without supplementation; Veg + Suppl, vegetarian diet with supplemental creatine and $\beta$-alanine; VDBP, vitamin-D-binding protein.

* Corresponding author: W. Derave, email Wim.derave@ugent.be. 
micronutrients, because they are ingested in relatively high amounts (range of $0 \cdot 1-5 \mathrm{~g} / \mathrm{d}$ ), nor as macronutrients, because they are not primarily serving an energy provision role. Yet, although not essential, carnitine, carnosine and creatine are nitrogenous molecules that possess properties with relevance to muscle metabolism and function. Phosphorylated creatine plays a crucial bioenergetic role in tissues with high metabolic demand by rephosphorylating ADP to synthesise ATP ${ }^{(5)}$. Carnitine is known to play a key role within several cellular energy producing pathways such as the transport of long-chain fatty acids into the mitochondria ${ }^{(6-8)}$. It is of highest abundance in meat; however, it is also present in a number of non-meat nutrients (e.g. nuts, potatoes, milk). In contrast, the dipeptide carnosine ( $\beta$-alanyl-t-histidine) is exclusively present in meat and fish. Carnosine has a wide spectrum of bioactive properties such as $\mathrm{pH}$ buffering, $\mathrm{Ca}^{2+}$ regulation, anti-glycation and antioxidant activity ${ }^{(9)}$. Numerous studies in the literature demonstrated the beneficial effects of creatine, carnitine (combined with carbohydrates) or $\beta$-alanine (precursor amino-acid of carnosine) supplementation on exercise performance in athletes ${ }^{(10-12)}$, and therapeutic potential towards certain disorders in which muscle function is a key component ${ }^{(5,13,14)}$.

Cross-sectional studies suggested that the homeostasis of carnitine, creatine and carnosine in humans is negatively affected by long-term vegetarianism. Somewhat lower plasma carnitine concentrations in vegetarians than in omnivores are reported $^{(15-18)}$, but no consistency exists regarding muscle carnitine content. Stephens et al. ${ }^{(18)}$ reported $17 \%$ lower muscle total carnitine concentrations in vegetarian women, whereas no differences were found in same measure in the study of Novakova et al. ${ }^{(15)}$. Until now, no longitudinal intervention study in human volunteers has investigated the effect on carnitine homeostasis of transiently switching omnivores onto a vegetarian diet. It is known, however, that carnitine has a slow turnover rate $(300-500 \mu \mathrm{mol} / \mathrm{d})^{(6)}$ and, as it is still somewhat present in a vegetarian diet, it can be suggested that carnitine homeostasis would be maintained during the 1st months of vegetarianism.

Chronic and complete restriction of dietary creatine and carnosine has been demonstrated to result in lower plasma creatine $^{(16)}$ and decreased intramuscular creatine ${ }^{(19)}$ and carnosine $e^{(20,21)}$ concentrations as compared with omnivorous subjects in cross-sectional studies. Thus, these reports suggest that the endogenous synthesis capacity may not be sufficient to maintain muscle creatine and carnosine concentrations, and therefore muscle availability, the principal site of storage, may depend on habitual dietary intake. Creatine is known to have a far higher turnover rate (approximately $2 \mathrm{~g} / \mathrm{d})^{(22)}$ than carnitine ${ }^{(6)}$ and carnosine ${ }^{(23)}$. Consequently, a 3 -week vegetarian intervention in omnivorous subjects resulted in a $10 \%$ decline in muscle creatine content $^{(24)}$ and longer-term interventions might thus even deplete creatine to a greater extent. On the contrary, a 5-week vegetarian intervention study indicated no significant reduction in muscle carnosine content ${ }^{(25)}$. However, in contrast to carnitine, carnosine is completely absent in vegetarian diets, suggesting that carnosine homeostasis might be affected by longer-term interventions.

This study aimed therefore to investigate the effect of a 6-month vegetarian diet on body creatine, carnitine and carnosine stores in omnivorous women. We hypothesised that homeostasis of creatine and carnosine would be disrupted when their dietary intake was missing. For carnitine, however, we hypothesised that homeostasis can be maintained given its slow turnover rate and its presence in some non-meat nutrients. A second aim was to investigate whether supplementation of creatine and $\beta$-alanine (the rate-limiting precursor of carnosine synthesis), concurrently with a lacto-ovo-vegetarian diet, was able to correct for potentially emerging deficiencies. Third, we aimed to investigate whether disturbed homeostasis of creatine or carnosine affects outcomes of an incremental cycling test. This type of exercise was chosen because previous studies demonstrated beneficial effects of both creatine or $\beta$-alanine supplementation on time to exhaustion (TTE) during an incremental cycling test ${ }^{(26,27)}$.

\section{Methods}

Subjects

Forty healthy female omnivores volunteered to participate in this 6-month intervention study. Only women were included in order to reduce the variability in baseline values of muscle carnosine, which is known to be dependent on sex ${ }^{(28)}$. Exclusion criteria were smoking, chronic use of medication, athletes participating in competitions, vegetarianism or eating meat or fish $<5$ times a week. One woman dropped out within 2 months for personal reasons. None of the subjects was taking supplements containing creatine, carnosine, $\beta$-alanine or carnitine in the 3 months before the start of the study. This study was conducted according to the guidelines laid down in the Declaration of Helsinki and all procedures involving human subjects were approved by the local ethics committee (Ghent University Hospital, Belgium; 2012/666). Written informed consent was obtained from all subjects. Registry name of this study is 'Creatine, Carnitine and Carnosine in Vegetarians' and identification no. is NCT03194334 (https://register.clinicaltrials. gov/prs/app/action/SelectProtocol?sid=S00077UP\&selectaction= Edit\&uid=U0002EMW\&ts=2\&cx=3y2e $4 \mathrm{y}$ ).

\section{Study design}

The study was scheduled over a period of 6 months and measurements were performed 1 week before the intervention (0 months; $0 \mathrm{M})$, after 3 months (3M) and within the last week (6M). In all, ten women continued their omnivorous diet throughout the entire study (controls) and the other twenty-nine subjects switched to a lacto-ovo-vegetarian diet for 6 months. The vegetarian group was split in two groups, matched for age, weight, height and baseline carnosine concentrations in soleus and gastrocnemius medialis muscles on group level. A total of fourteen of them were supplemented with $\beta$-alanine and creatine (Veg + Suppl) and the other fifteen women received a placebo (Veg + Pla) (Fig. 1). A co-worker, not involved in the study design and analysis, performed the randomisation and prepared the containers with supplements. With regard to supplementation, the study was a double-blind placebo-controlled study. The lactoovo-vegetarian diet consisted of vegetables, fruits, seeds, grains, meat substitutes, eggs and dairy products and the exclusion of 


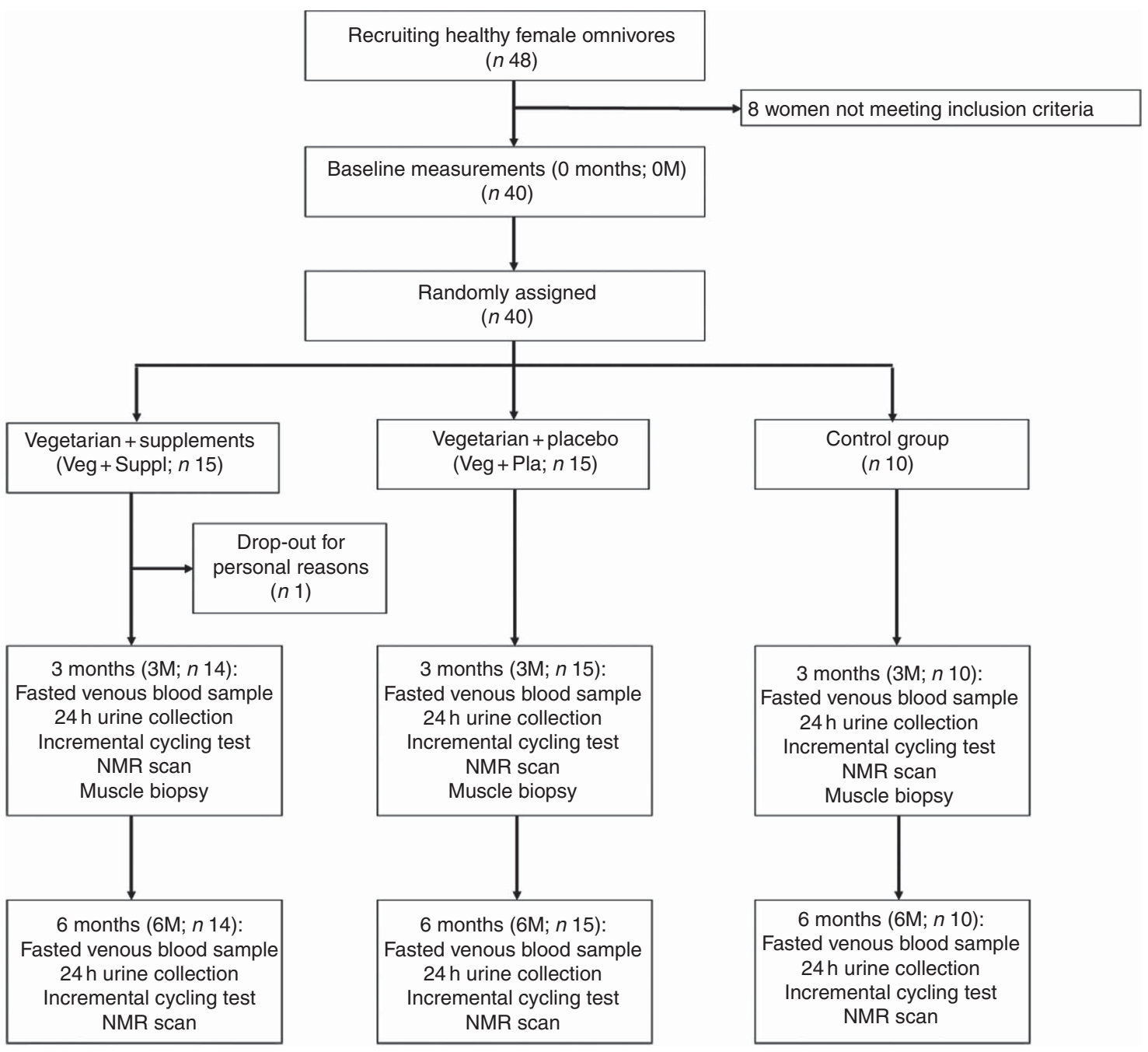

Fig. 1. Participant flow chart.

meat, poultry and fish. Subjects were asked to complete a 3-d food diary at the start and after 3 months and received nutritional advice by a dietitian during the study to prevent deficiencies in macronutrients and micronutrients. Furthermore, vegetarian recipes were provided by email to support the subjects in their vegetarian diet.

\section{Supplements}

The supplementation protocol included simultaneously daily oral administration of creatine monohydrate (Creapure $^{\circledR}$; AlzChem AG) and slow-release $\beta$-alanine (Carnosyn ${ }^{\circledR}$; Natural Alternatives International) or a placebo (maltodextrin; Natural Spices). The supplements are considered safe and efficacious ${ }^{(29,30)}$. The Veg + Suppl group ingested $1 \mathrm{~g}$ of creatine monohydrate (two capsules of $500 \mathrm{mg}$ ) and $0.8 \mathrm{~g}$ of $\beta$-alanine (one Carnosyn ${ }^{\circledR}$ tablet) each day for the first 3 months. Intermediate analysis of muscle carnosine content at 3 months revealed that $0.8 \mathrm{~g}$ of $\beta$-alanine was too high to maintain carnosine at baseline concentration, and therefore the $\beta$-alanine dose was reduced to $0.4 \mathrm{~g} / \mathrm{d}$ during the last 3 months of the study, with creatine dosing remaining at $1 \mathrm{~g} / \mathrm{d}$. The Veg + Pla group was supplemented with an identical number of capsules and tablets of maltodextrin. Subjects were instructed to take the supplements together with a meal, as this was shown to improve muscle metabolite loading ${ }^{(31,32)}$. All subjects were asked not to take any other supplements than those provided by the current study. Compliance was checked by asking the subjects to return the containers and counting the pills that were left. The Veg + Pla group and the Veg + Suppl group ingested 94.4 (SD 5.4)\% and 96.4 (SD 4.8)\% of creatine/ placebo pills, respectively. Compliance ranged between 81.7 and $100 \%$. For the $\beta$-alanine/placebo tablets, the Veg + Pla group and the Veg + Suppl group ingested $96.6 \%$ (sD 3.7) \% and $98 \cdot 1$ (SD $2 \cdot 1$ ) \%, respectively, and compliance ranged between 88.3 and $100 \%$. Because all subjects ingested more than $80 \%$ of the supplements, no subjects were excluded based on compliance. The control group, in which the participants remained on an omnivorous diet, did not receive any supplements.

\section{Incremental cycling test}

At $0 \mathrm{M}, 3 \mathrm{M}$ and $6 \mathrm{M}$, subjects performed an incremental cycling test. On the first visit, subjects were screened to be medically fit before starting the incremental cycling protocol to exhaustion. 
The test was performed on an electrically braked cycling ergometer (Excalibur; Lode). $\mathrm{VO}_{2}$ was measured continuously via a computerised breath-by-breath system (Jaeger Oxycon Pro). Following a 3-min warm-up at $40 \mathrm{~W}$, the workload was increased by $40 \mathrm{~W}$ every $3 \mathrm{~min}$ until the point the subjects failed to continue to pedal at $60 \mathrm{rpm}$. Capillary blood samples were taken before and immediately after the incremental cycling test, and $\mathrm{pH}$ and lactate were measured (blood gas analysis: GEM, Premier TM 3000; Instrumentation Laboratory).

\section{Sample collection}

Blood samples were collected from a forearm vein after an 8-h overnight fast into heparin plasma tubes and serum gel tubes after $0 \mathrm{M}, 3 \mathrm{M}$ and $6 \mathrm{M}$. Heparin tubes were immediately centrifuged $(5 \mathrm{~min}, 16000 \mathrm{~g}$ ) after collection to separate plasma. Serum tubes were left at rest at room temperature to obtain complete coagulation, before performing the same centrifugation process as for plasma. All samples were frozen at $-20^{\circ} \mathrm{C}$ until subsequently analysed. True-cut muscle biopsies were taken at baseline and after $3 \mathrm{M}$ from the vastus lateralis of the left leg at rest. Following local anaesthesia of the skin and subcutaneous tissues with $5 \mathrm{ml}$ lidocaine, two muscle samples were taken with a 14-gauge true-cut biopsy needle (Bard Magnum Biopsy gun; Bard, Inc.). The muscle samples were then immediately frozen in liquid $\mathrm{N}_{2}$ and stored at $-80^{\circ} \mathrm{C}$ until subsequent analysis. A far too low number of subjects consented to have muscle biopsies taken at $6 \mathrm{M}$. Therefore, muscle analyses were restricted to the $0 \mathrm{M}$ and $3 \mathrm{M}$ time points (Fig. 1). Urine samples ( $24 \mathrm{~h}$ collection) were collected at baseline and after $3 \mathrm{M}$ and $6 \mathrm{M}$ into a plastic container and a 5-ml aliquot was stored at $-20^{\circ} \mathrm{C}$.

\section{Quantification of 25-hydroxyvitamin D}

25-Hydroxyvitamin D was measured in serum samples of all participants using the Elecsys Vitamin D total assay (Cobas Instrument). In brief, the assay kit uses a vitamin-D-binding protein (VDBP) as capture protein to bind vitamin $\mathrm{D}_{3}$ and $\mathrm{D}_{2}$. First, the sample $(15 \mu \mathrm{l})$ is incubated with pretreatment reagent 1 and 2 for 9 min. Thereby, the natural VDBP in the sample is denatured to release the bound vitamin D $(25-\mathrm{OH})$. Second, the sample is further incubated with a recombinant ruthenium-labelled VDBP to form a complex of vitamin D $(25-\mathrm{OH})$ and the ruthenylated-VDBP. Third, with the addition of a biotinylated vitamin D (25-OH), a complex consisting of the ruthenium-labelled VDBP and the biotinylated vitamin D $(25-\mathrm{OH})$ is formed. The entire complex becomes bound to the solid phase (by the interaction of biotin and streptavidin-coated microparticles, which are magnetically captured on the surface of the elecrode). Unbound substances are removed with ProCell/ProCell M. Applying voltage to the electrode induces chemiluminescent emission, which is measured by a photomultiplier. Results are determined via an instrument-specific calibration curve, which is generated by two-point calibration and a calibration master curve provided via the reagent barcode.

\section{Quantification of plasma and urinary compounds}

Plasma creatine, creatinine, guanidinoacetate, carnitine and acetylcarnitine were measured by liquid chromatography-double
MS (LC-MSMS) with butanol-HCl derivatisation. Creatine, creatinine and guanidinoacetate were quantified as previously described $^{(33)}$. For plasma carnitine and acetylcarnitine, $400 \mu \mathrm{l}$ of methanol were added to $100 \mu \mathrm{l}$ of each plasma sample. Vials were mixed for $2 \mathrm{~min}$, incubated for $1 \mathrm{~h}$ at $8^{\circ}$ and centrifuged for $15 \mathrm{~min}$ at $16000 \mathrm{~g}$. The supernatant $(50 \mu \mathrm{l})$ was evaporated to dryness under $\mathrm{N}_{2}$ at room temperature. The remaining residues were subsequently derivatised with $50 \mu \mathrm{l}$ of butanol-HCl. Samples were dried again under $\mathrm{N}_{2}$ at $45^{\circ} \mathrm{C}$, and $100 \mu$ lof mobile phase $(80 \%$ methanol) was added. We injected $5 \mu \mathrm{l}$ in the LC-MSMS system. Urinary creatinine was measured using the Cobas Instrument (Roche). Plasma $\beta$-alanine and urinary biomarkers for meat intake (pi-methylhistidine, tau-methylhistidine and anserine) were measured by HPLC. Plasma and urine of all participants at three time points were deproteinised using 35\% sulfosalicylic acid and centrifuged (16000 $\boldsymbol{g}$ for $5 \mathrm{~min}$ ). Two-point $6 \mu$ lof deproteinised supernatant was mixed with $77.4 \mu \mathrm{l}$ of AccQ Fluor Borate buffer and $20 \mu \mathrm{l}$ of reconstituted Fluor Reagent from the AccQTag chemistry kit (Waters). The same method was applied to the combined standard solutions of $\beta$-alanine (Sigma) for plasma, and pi-methylhistidine (Sigma), tau-methylhistidine (Sigma) and anserine (Sigma) for urine. The derivatised samples were applied to a Waters HPLC system with the following parameters: AccQTag column $(3.9 \times 150 \mathrm{~mm}, 5 \mu \mathrm{m})$ for $\beta$-alanine quantification and Xbridge BEH column $(4.6 \times 150 \mathrm{~mm}, 2.5 \mu \mathrm{m})$ for pi-methylhistidine, tau-methylhistidine and anserine quantification, both with fluorescence detector (excitation/emission wavelength: 250/ $395 \mathrm{~nm}$ ). The column was equilibrated with buffer A (10\% eluent A (Waters) - $\left.90 \% \mathrm{H}_{2} \mathrm{O}\right)$, buffer $\mathrm{B}(100 \%$ acetonitrile) and buffer $\mathrm{C}$ $\left(100 \% \mathrm{H}_{2} \mathrm{O}\right)$ at a flow rate of $1 \mathrm{ml} / \mathrm{min}$ at room temperature.

\section{Quantification of muscle carnitine and creatine}

Wet muscle samples were frozen in liquid $\mathrm{N}_{2}$ and subsequently freeze-dried before being powdered and checked for all visible blood and connective tissue, which were removed under low-grade microscopy. Then muscle metabolites were extracted by adding cold $0.5 \mathrm{~m}$ perchloric acid (PCA, containing $1 \mathrm{~mm}$ EDTA) to the muscle powder while on ice in a ratio of $1 \mathrm{ml}$ of PCA:every $12.5 \mathrm{mg}$ of muscle powder. Then, samples were gently vortexed for $10 \mathrm{~min}$ before being centrifuged $\left(10000 \mathrm{rpm}\right.$ for $3 \mathrm{~min}$ at $\left.4^{\circ} \mathrm{C}\right)$. Supernatants were then carefully removed to new test tubes and neutralised with $2 \cdot 2 \mathrm{M} \mathrm{KHCO}_{3}$. The perchlorate precipitates were removed by centrifugation ( $10000 \mathrm{rpm}$ for $3 \mathrm{~min}$ at $4^{\circ} \mathrm{C}$ ), and the supernatants (metabolite extracts) were removed to new test tubes and stored at $-80^{\circ} \mathrm{C}$ for subsequent analysis. Muscle PCA extracts were used to determine muscle total creatine content and free and acetylcarnitine content using spectrophotometric and radioactive methods described by Harris et $a l^{(34)}$ and Cederblad et al. ${ }^{(35)}$, respectively. Muscle total creatine and carnitine contents were expressed as the sum of creatine and phosphocreatine, and the sum of free and acetylated carnitine, respectively.

\section{Proton magnetic resonance spectroscopy}

The carnosine levels in soleus and gastrocnemius muscles of all subjects at $0 \mathrm{M}, 3 \mathrm{M}$ and $6 \mathrm{M}$ was measured by proton magnetic resonance spectroscopy ( $\left.{ }^{1} \mathrm{H}-\mathrm{MRS}\right)$, as previously described ${ }^{(36)}$. The subjects were lying in supine position and the lower leg 
was fixed in a holder with the angle of the ankle at $20^{\circ}$ plantar flexion. All the MRS measurements were performed with a 3 Tesla whole-body MRI scanner (Siemens Trio) equipped with a spherical knee-coil. Single-voxel point-resolved spectroscopy (PRESS) sequence with the following parameters was used: repetition time $(\mathrm{TR})=2.000 \mathrm{~ms}$, echo time $(\mathrm{TE})=30 \mathrm{~ms}$, number of excitations $=128,1.024$ data points, spectral bandwidth of $1.200 \mathrm{~Hz}$ and a total acquisition time of $4.24 \mathrm{~min}$. The average voxel size was $40 \times 10 \times 28 \mathrm{~mm}$ for soleus and $40 \times 11 \times 29 \mathrm{~mm}$ for gastrocnemius and the line width of the water signal was on average $25.2 \mathrm{~Hz}$ (soleus) and $28.3 \mathrm{~Hz}$ (gastrocnemius), following shimming procedures. The absolute carnosine content (in mm) was calculated as described before by Baguet et al. ${ }^{(36)}$.

\section{Statistics}

A one-way ANOVA was performed to compare the difference in baseline values (age, height, weight, BMI, muscle carnosine concentration and $\mathrm{VO}_{2 \max }$ ). A $3 \times 3$ repeated-measures ANOVA with baseline values of each parameter as a covariate (ANCOVA) was used to evaluate plasma and urinary metabolite concentrations, muscle carnosine, TTE and $\mathrm{VO}_{2 \max }$ with 'group' (Veg + Suppl; Veg + Pla; control) as between-subject factor and 'time' $(0 \mathrm{M} ; 3 \mathrm{M} ; 6 \mathrm{M})$ as within-subject factor (SPSS statistical software; SPSS Inc.). For the analysis of capillary lactate and $\mathrm{pH}$, measurements before and after the incremental cycling test were included as another within-subject factor (start; end). In case of significance, analyses were repeated for each group separately and pairwise comparisons were used to compare the different time points. A $3 \times 2$ repeated-measures ANCOVA (with baseline values of each parameter as a covariate) was used to analyse muscle biopsy metabolite content and dietary macronutrient intake with 'group' (Veg + Suppl; Veg + Pla; control) as betweensubject factor and 'time' $(0 \mathrm{M} ; 3 \mathrm{M})$ as within-subject factor. In case of significance, pairwise comparisons were performed to compare 0 to 3 months for each group separately. Correlations between serum 25-hydroxyvitamin D and plasma and muscle carnitine concentrations were obtained by means of Pearson's correlations. Values are presented as means and standard deviations and statistical significance threshold was set at $P \leq 0.05$.

The sample size was calculated in accordance with the primary outcome of the trial: a total sample size of twenty-four subjects is necessary to detect an effect size of 0.25 of a vegetarian diet on muscle creatine, as we know that muscle creatine declines following a 22 -d vegetarian diet ${ }^{(24)}$. The sample size of fifteen subjects in each vegetarian group was thus chosen to warrant for drop-out as the study is a long-term intervention. As the study was less onerous for the control group and investigated variables were hypothesised to be constant following an omnivore diet, only ten subjects were included in this group.

\section{Results \\ Participants}

At the start of the study, the age, weight, height and BMI of the sample as a whole was $25.6(\mathrm{sD} 7 \cdot 3$ ) years, $62.7(\mathrm{sD} 7.9) \mathrm{kg}$, $168(\mathrm{sD} 6 \cdot 3) \mathrm{cm}$ and $22.3(\mathrm{sD} 2 \cdot 6) \mathrm{kg} / \mathrm{m}^{2}$, respectively. After the participants were assigned to their group, no significant differences emerged for age, weight, height and BMI (Table 1). Furthermore, there was no significant difference in baseline muscle carnosine levels for both soleus and gastrocnemius (Table 1). The groups did not differ in physical fitness determined by $\mathrm{VO}_{2 \max }$ values (control: 40.4 (sD 6.4) $\mathrm{ml} / \mathrm{min}$ per $\mathrm{kg}$, $\mathrm{Veg}+\mathrm{Pla}: 39 \cdot 4(\mathrm{sD} \quad 6 \cdot 4) \mathrm{ml} / \mathrm{min}$ per $\mathrm{kg}, \quad \mathrm{Veg}+\mathrm{Suppl}: 36 \cdot 6$ (sD 6.3$) \mathrm{ml} / \mathrm{min}$ per $\mathrm{kg} ; P=0.504)$.

\section{Compliance contro/ via urinary biomarkers for meat intake}

Both dietary meat intake urinary markers pi-methylhistidine and anserine were significantly lower or revealed a trend to significance at $6 \mathrm{M}$ than at $\mathrm{OM}$ in the $\mathrm{Veg}+\mathrm{Pla}$ and $\mathrm{Veg}+$ Suppl groups (pi-methylhistidine: $P=0.006$ and $P=0.004$, anserine: $P=0.075$ and $P=0.048$, respectively), but not in the control group (pi-methylhistidine: $P=0.411$; anserine: $P=0.526$ ) (Table 2). Although urinary tau-methylhistidine excretion at $6 \mathrm{M}$ was significantly lower than at $0 \mathrm{M}$ in all experimental groups, the magnitude of this decline was more pronounced in the Veg $+\mathrm{Pla}$ and Veg + Suppl groups than in the control group.

Table 1. Baseline values of the three experimental groups (Mean values and standard deviations)

\begin{tabular}{|c|c|c|c|c|c|c|}
\hline & \multicolumn{2}{|c|}{ Control } & \multicolumn{2}{|c|}{$\mathrm{Veg}+\mathrm{Pla}$} & \multicolumn{2}{|c|}{ Veg + Suppl } \\
\hline & Mean & SD & Mean & SD & Mean & SD \\
\hline Age (years) & 25.9 & 9.0 & $25 \cdot 4$ & $7 \cdot 1$ & 25.5 & $6 \cdot 6$ \\
\hline Weight $(\mathrm{kg})$ & 59.0 & $6 \cdot 7$ & $63 \cdot 3$ & $6 \cdot 6$ & 64.8 & 9.5 \\
\hline Height (cm) & 168 & $6 \cdot 6$ & 169 & $5 \cdot 1$ & 167 & $7 \cdot 6$ \\
\hline BMI $\left(\mathrm{kg} / \mathrm{m}^{2}\right)$ & $21 \cdot 0$ & $2 \cdot 3$ & $22 \cdot 3$ & $2 \cdot 2$ & $23 \cdot 2$ & $2 \cdot 9$ \\
\hline Carnosine soleus (mм) & 3.9 & 0.4 & 3.5 & 0.4 & 3.7 & $1 \cdot 1$ \\
\hline Carnosine gastrocnemius (mM) & $5 \cdot 2$ & 1.2 & $5 \cdot 2$ & 1.5 & $5 \cdot 1$ & 1.6 \\
\hline
\end{tabular}

Veg + Pla, vegetarian + placebo; Veg + Suppl, vegetarian + supplemental creatine and $\beta$-alanine.

Table 2. Urinary concentrations of the meat-intake biomarkers pi-methylhistidine, tau-methylhistidine and anserine for the three experimental groups at baseline (0 months; $0 \mathrm{M}), 3$ months (3M) and 6 months (6M) analysed by a repeated-measures ANOVA

(Mean values and standard deviations)

\begin{tabular}{|c|c|c|c|c|c|c|}
\hline & \multicolumn{2}{|c|}{$\mathrm{OM}$} & \multicolumn{2}{|c|}{$3 \mathrm{M}$} & \multicolumn{2}{|c|}{$6 \mathrm{M}$} \\
\hline & Mean & SD & Mean & SD & Mean & SD \\
\hline \multicolumn{7}{|c|}{ Pi-methylhistidine (mg/24h) } \\
\hline Control & 161.9 & 111.2 & $117 \cdot 8$ & 124.8 & 122.5 & $168 \cdot 8$ \\
\hline Veg + Pla & $167 \cdot 4$ & $145 \cdot 3$ & $26 \cdot 4^{*}$ & $10 \cdot 7$ & $15 \cdot 1^{*}$ & 4.7 \\
\hline Veg + Suppl & 212.9 & $201 \cdot 0$ & $28 \cdot 7^{\star}$ & 9.1 & $18 \cdot 0^{*}$ & $6 \cdot 7$ \\
\hline \multicolumn{7}{|c|}{ Tau-methylhistidine (mg/24 h) } \\
\hline Control & 55.2 & $25 \cdot 3$ & 74.6 & 61.6 & $42 \cdot 6^{\star}$ & 21.5 \\
\hline Veg + Pla & $63 \cdot 1$ & $20 \cdot 0$ & $43 \cdot 1^{\star}$ & $15 \cdot 3$ & $27 \cdot 6^{\star \star}$ & $7 \cdot 1$ \\
\hline Veg + Suppl & 63.0 & $22 \cdot 3$ & $46 \cdot 1^{*}$ & $16 \cdot 0$ & $26 \cdot 5^{\star \star}$ & 8.5 \\
\hline \multicolumn{7}{|c|}{ Anserine (mg/24h) } \\
\hline Control & $15 \cdot 0$ & $14 \cdot 3$ & 9.5 & 7.4 & 11.6 & $23 \cdot 2$ \\
\hline Veg + Pla & $9 \cdot 2$ & 7.9 & $5 \cdot 5$ & $2 \cdot 9$ & $4.0 \dagger$ & 1.9 \\
\hline Veg + Suppl & $10 \cdot 7$ & $12 \cdot 9$ & $4.4 \dagger$ & $2 \cdot 2$ & $2 \cdot 6^{\star}$ & 1.1 \\
\hline
\end{tabular}

Veg + Pla, vegetarian + placebo; Veg + Suppl, vegetarian + supplemental creatine and $\beta$-alanine.

* $P<0.05$ compared with $0 \mathrm{M}$; ${ }^{* *} P<0.001$ compared with $0 \mathrm{M}$.

† $0.05<P<0.10$ compared with $0 \mathrm{M}$. 
(a)

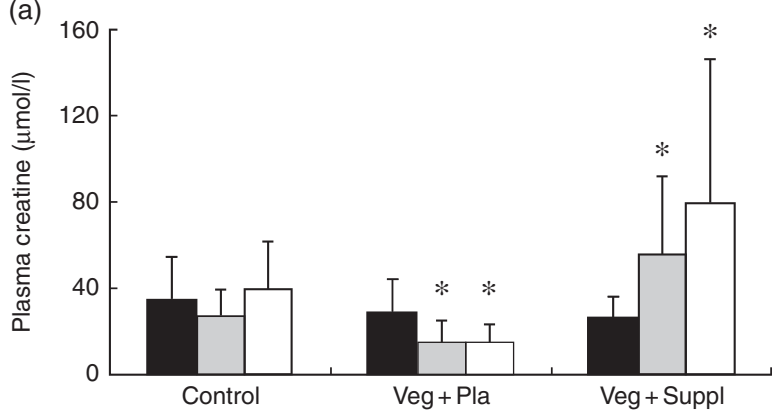

(c)

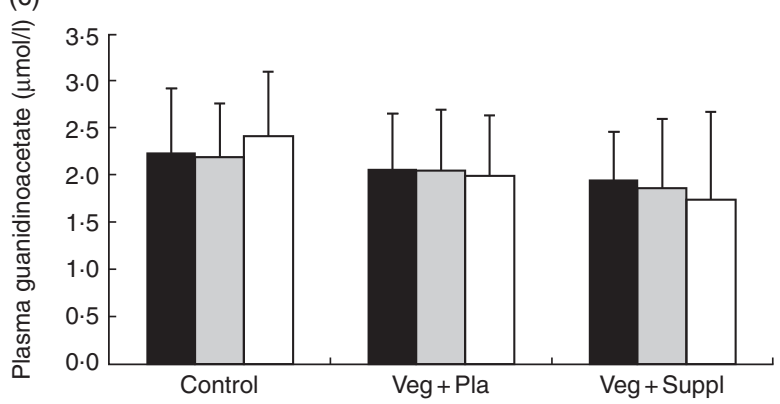

(b)

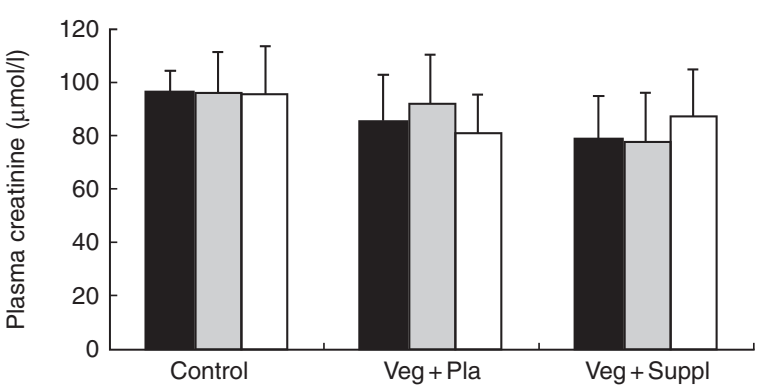

(d)

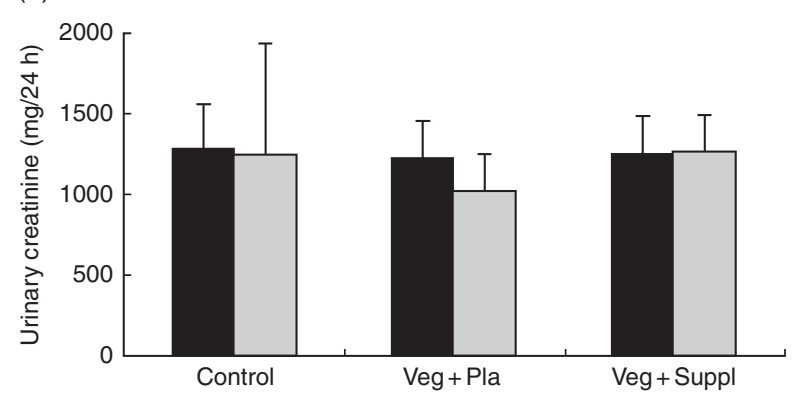

Fig. 2. Effect of an omnivorous diet (control), a vegetarian diet $(V e g+P l a)$ and a vegetarian diet combined with creatine and $\beta$-alanine supplements $($ Veg + Suppl) on (a) plasma creatine, (b) plasma creatinine, (c) plasma guanidinoacetate and (d) urinary creatinine concentrations, analysed by a repeated-measures ANCOVA. Values are means and standard deviations represented by vertical bars. $\square$, Baseline (0 months); $\square, 3$ months; $\square, 6$ months. ${ }^{*} P<0.05$ compared with baseline.

\section{Creatine moieties}

To evaluate the effect of a long-term vegetarian diet in previous omnivores on creatine moieties, plasma creatine (Fig. 2(a)), creatinine (Fig. 2(b)) and guanidinoacetate (Fig. 2(c)), urinary creatinine (Fig. 2(d)) and muscle total creatine (Fig. 3) were measured. For plasma creatine, a significant interaction effect $(P<0.001)$ was found (Fig. 2(a)), demonstrating a decrease of $46 \%$ from baseline in the Veg + Pla group $(P=0.008)$ and an increase of $195 \%$ in the Veg + Suppl group $(P=0.008)$ after 6 months. Plasma creatinine $(P=0 \cdot 102)$, guanidinoacetate $(P=0.414)$ and urinary creatinine $(P=0.344)$ were not influenced by any intervention. As can be seen in Fig. 3 , a significant interaction effect $(P=0.017)$ was found for muscle total creatine. Adhering to a creatine-poor vegetarian diet for 3 months caused a significant decline $(14.6 \%)$ in muscle total creatine (153.5 (SD 24.0) to 128.8 (sD 11.6 ) $\mathrm{mmol} / \mathrm{kg}$ dry weight $(\mathrm{dw}) ; P=0.009)$, whereas this was slightly increased in the Veg + Suppl $(9.7 \%)$ and control $(6.8 \%)$ groups $(P=0.387$ and $P=0.068$, respectively).

\section{Carnitine moieties}

Plasma and muscle free carnitine, acetylcarnitine and total carnitine (free + acetylcarnitine forms) concentrations were measured to investigate the effect of induced vegetarianism on the carnitine moieties in previous omnivore subjects. No significant interaction effect was found for any of these parameters. However, as shown in Fig. 4(a)-(c) and 5(a)-(c), significant main effect of time for plasma carnitine $(P=0.003)$, acetylcarnitine $(P=0.002)$ and total carnitine $(P=0.001)$, and muscle carnitine $(P=0.049)$ and total carnitine $(P=0.001)$ were found. As most of the carnitine parameters seem to decline

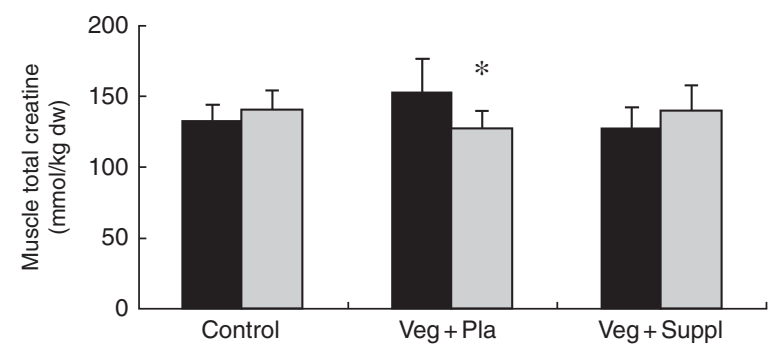

Fig. 3. Effect of an omnivorous diet (control), a vegetarian diet (Veg + Pla) and a vegetarian diet combined with creatine and $\beta$-alanine supplements $(V e g+$ Suppl) on muscle total creatine content analysed by a repeatedmeasures ANCOVA. Values are means and standard deviations represented by vertical bars. $\square$, Baseline (0 months; $0 \mathrm{M}) ; \square, 3$ months; dw, dry weight. * $P<0.05$ compared with $0 \mathrm{M}$.

independently from intervention, but rather as a result of a seasonal pattern, especially towards the $3 \mathrm{M}$ time point that coincided with the end of the winter, we decided, therefore, to evaluate whether carnitine seasonal pattern could be related to the vitamin D status.

\section{Serum 25-hydroxyvitamin D}

Similar to most of the carnitine forms, a significant main effect of time $(P<0 \cdot 001)$ for serum 25 -hydroxyvitamin D concentration was found, exemplified by a significant decrease from 0 to $3 \mathrm{M}$ and a return to baseline at 6M (Fig. 6(a)). To check whether the 25-hydroxyvitamin D levels were the underlying mechanism for the observed pattern of carnitine levels in plasma and muscle, correlations between these parameters were explored. Surprisingly, a significant negative rather than positive 
(a)
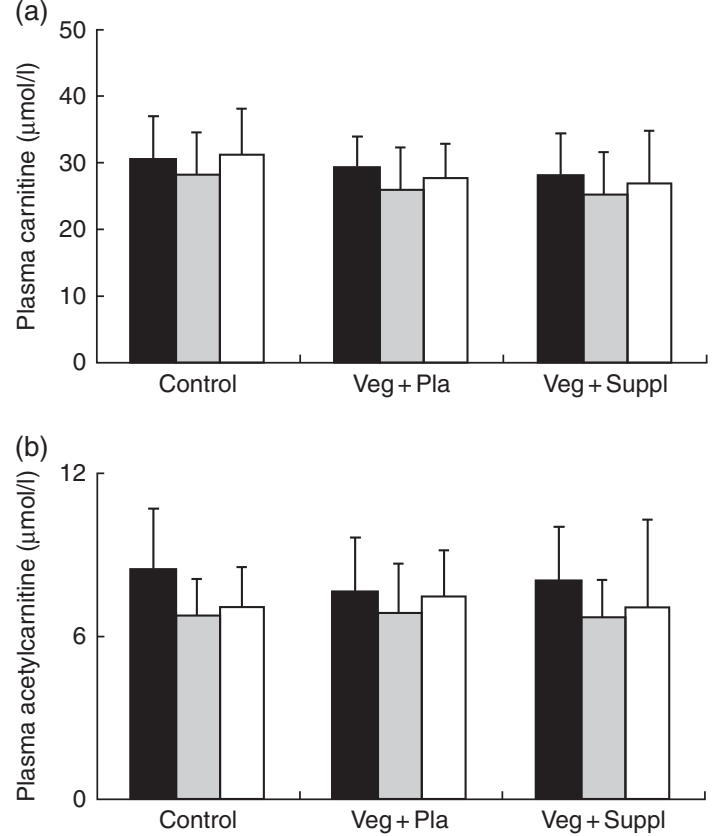

(c)

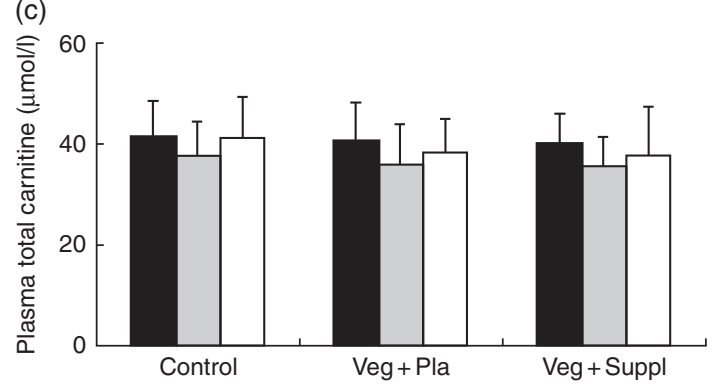

Fig. 4. Effect of an omnivorous diet (control), a vegetarian diet $(\mathrm{Veg}+\mathrm{Pla})$ and a vegetarian diet combined with creatine and $\beta$-alanine supplements (Veg + Suppl) on (a) plasma carnitine, (b) plasma acetylcarnitine and (c) plasma total carnitine concentrations, analysed by a repeated-measures ANCOVA. For all these parameters, a significant main effect of time was found $(P=0.003 ; P=0.002$; $P=0.001$, respectively). Values are means and standard deviations represented by vertical bars. $\square$, Baseline; $\square, 3$ months; $\square, 6$ months.

correlation between serum 25-hydroxyvitamin D levels and plasma total carnitine was observed at all time points $(r-0.34$, $P<0.001$ ) (Fig. 6(b)). No significant correlation between 25-hydroxyvitamin D levels and total muscle carnitine was observed $(r-0 \cdot 104, P=0 \cdot 422)$. After clustering the subjects in vitamin-D-deficient $(<25 \mathrm{ng} / \mathrm{ml}$ at $0 \mathrm{M}$ or $3 \mathrm{M})$ and non-deficient $(>25 \mathrm{ng} / \mathrm{ml})$ groups, significant or trend to significant higher total plasma carnitine levels in the deficient than in the non-deficient group were found at each time point $(0 M$, $P=0.013 ; 3 \mathrm{M}, P=0.064 ; 6 \mathrm{M}, P=0.002)$. 25-Hydroxyvitamin D-deficient subjects also displayed a significant lower decrease in vitamin D levels from $0 \mathrm{M}$ to $3 \mathrm{M}$ compared with non-deficient subjects $(-4.53 v .8 .50 \mathrm{ng} / \mathrm{ml}, P=0.014)$.

\section{Carnosine availability}

Fasting plasma $\beta$-alanine concentrations remained stable throughout the 6-month intervention period in the Veg+ Pla and control group, but not in the Veg + Suppl group (Fig. 7(a)). (a)

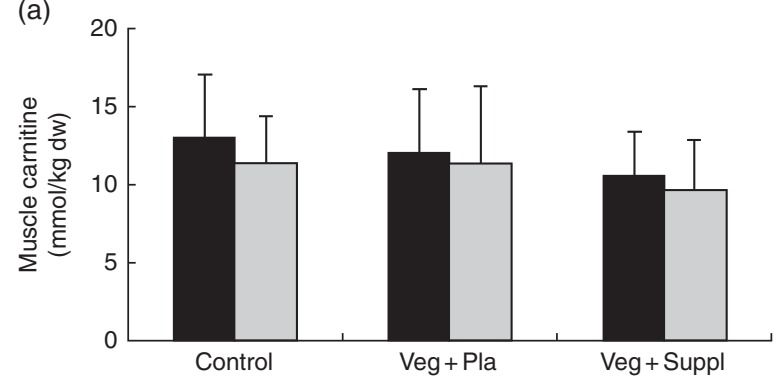

(b)
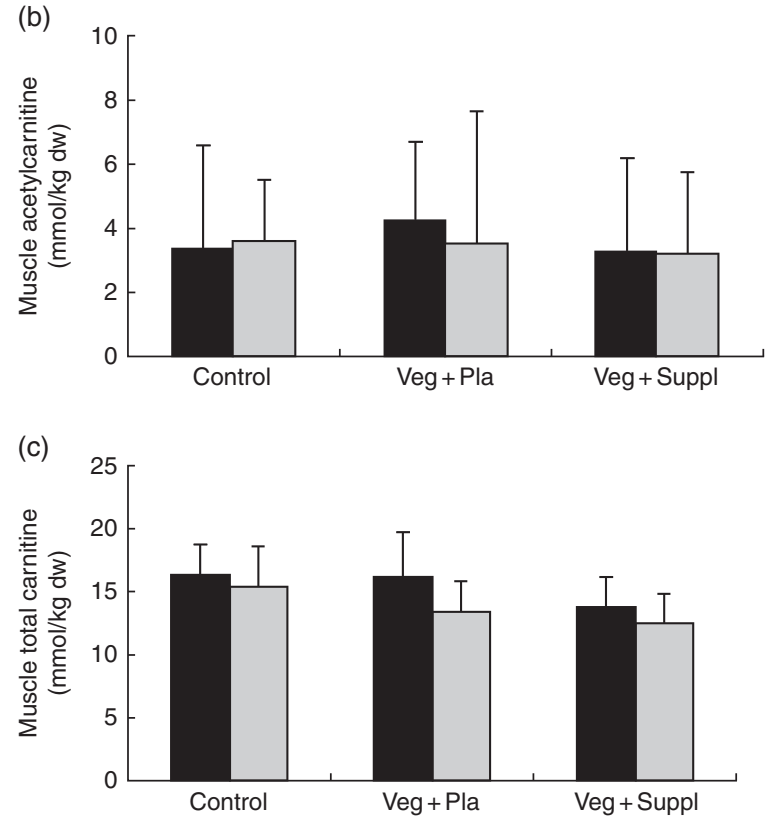

Fig. 5. Effect of an omnivorous diet (control), a vegetarian diet (Veg + Pla) and a vegetarian diet combined with creatine and $\beta$-alanine supplements (Veg + Suppl) on (a) muscle carnitine, (b) muscle acetylcarnitine (c) and muscle total carnitine content, analysed by a repeated-measures ANCOVA. For muscle carnitine and muscle total carnitine, a significant main effect of time was found $(P=0.049$ and $P=0.001$, respectively). Values are means and standard deviations represented by vertical bars. $\square$, Baseline; $\square$, 3 months; dw, dry weight.

The latter group showed a significant increase in plasma $\beta$-alanine concentrations after 3 months of vegetarian diet combined with $0 \cdot 8 \mathrm{~g}$ of $\beta$-alanine/d $(+27 \cdot 2 \% ; P=0 \cdot 027)$, with no further increase in the following 3 months when the daily dose of $\beta$-alanine was lowered to $0.4 \mathrm{~g} / \mathrm{d}$ ( $P=0.740 v .3$ months). A significant $(P=0.001)$ interaction effect (time $\times$ group) was found for soleus muscle carnosine content (Fig. 7(b)). In accordance with plasma $\beta$-alanine, soleus carnosine did not change over time in the Veg + Pla group $(P=0 \cdot 619)$, nor in the control group $(P=0.790)$. When a 6 -month vegetarian diet was combined with $\beta$-alanine supplementation (Veg + Suppl group), soleus carnosine content increased by $26 \%(P<0 \cdot 001)$. This increase was already established after 3 months ( $+28 \%$; $P<0 \cdot 001)$, with no further increase in the subsequent 3 months. For gastrocnemius muscle, similar results were found (Fig. 7(c)): a significant increase in the Veg + Suppl group of 28 and $41 \%$ after $3(P=0.009)$ and $6(P=0.001)$ months, respectively, whereas carnosine remained stable in the Veg $+\mathrm{Pla}(P=0 \cdot 275)$ and control group $(P=0.293)$. 

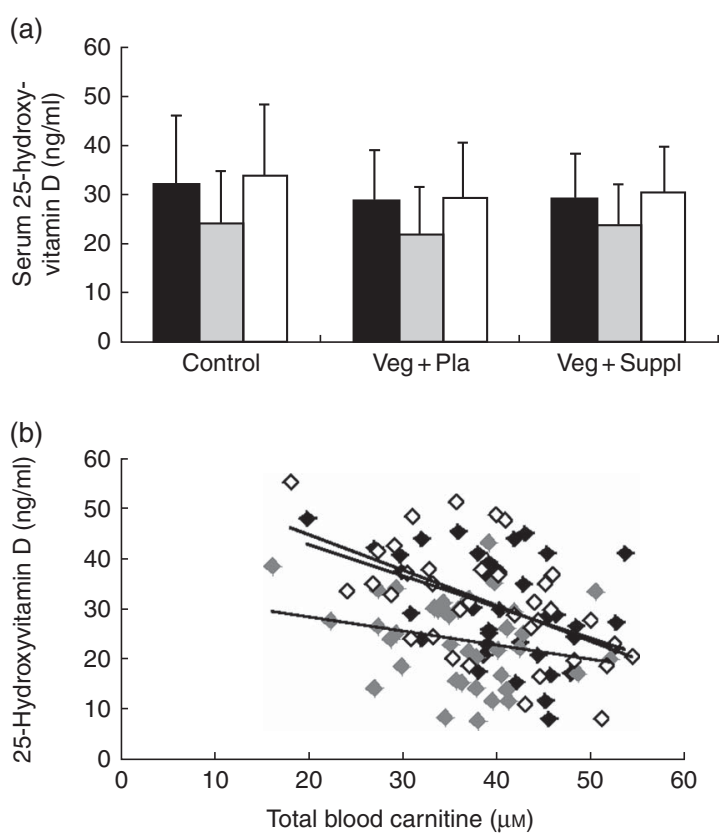

Fig. 6. Effect of an omnivorous diet (control), a vegetarian diet (Veg + Pla) and a vegetarian diet combined with creatine and $\beta$-alanine supplements (Veg + Suppl) on (a) serum 25-hydroxyvitamin $D$ concentrations analysed by a repeatedmeasures ANOVA and (b) correlations between 25-hydroxyvitamin $D$ and total plasma carnitine content at baseline (0 months; 0M) $(r-0.432, P=0.008)$, 3 months $(3 \mathrm{M})(r-0.24, P=0.153)$ and 6 months $(6 \mathrm{M})(r-0.561, P \leq 0.001)$, analysed by Pearson's correlation. Values are means and standard deviations represented by vertical bars. a: $\square, 0 \mathrm{M} ; \square, 3 \mathrm{M} ; \square, 6 \mathrm{M} ;$ b: $\diamond, 0 \mathrm{M} ; \diamond, 3 \mathrm{M} ; \diamond, 6 \mathrm{M}$.

\section{Incremental cycling test}

$\mathrm{VO}_{2 \max }$ and TTE did not differ between the experimental groups at baseline, nor did it change during the 6-month intervention period (Table 3). Blood lactate increased to a range of $11-14 \mathrm{mmol} / \mathrm{l}$ by the end of cycling. Blood $\mathrm{pH}$ at rest was approximately $7 \cdot 41-7.42$ and was not affected by the subsequent intervention (vegetarian/supplementation). The incremental cycling test elicited a marked acidosis $(\mathrm{pH} 7 \cdot 23-7 \cdot 29)$ in all intervention groups (Table 4$)$. These parameters $\left(\mathrm{VO}_{2 \max }\right.$, TTE, lactate and $\mathrm{pH}$ ) showed neither a significant intervention nor time or interaction effect.

\section{Dietary registration}

There was no significant difference between the vegetarian and control subjects concerning the daily intake of energy content, proteins, carbohydrates and fat through the regular diet both at the start $(0 \mathrm{M})$ and after 3 months $(3 \mathrm{M})(P>0.05$ for all variables) (Table 5). Although the vegetarian group seemed to have slightly higher total energy consumption, there was no group difference in energy consumption from each macronutrient (protein: $14.7 v \cdot 14.5 \%$; carbohydrates: $46 \cdot 4 v$. $44.6 \%$; fat: $35.6 v$. $35.7 \%$ for control and vegetarian subjects, respectively).

\section{Discussion}

The present study demonstrates that whole-body creatine homeostasis was disturbed by a 3-month vegetarian diet in omnivorous women, whereas carnosine and carnitine
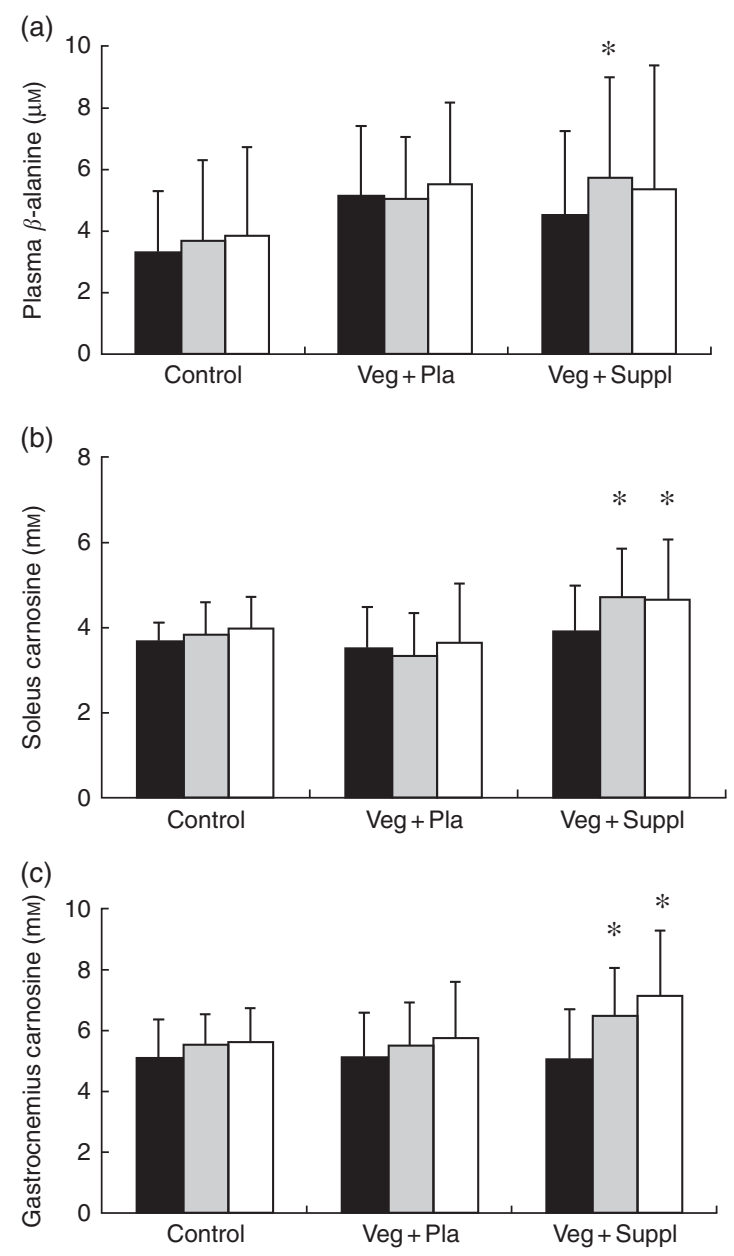

Fig. 7. Effect of an omnivorous diet (control), a vegetarian diet (Veg + Pla) and a vegetarian diet combined with creatine and $\beta$-alanine supplements (Veg + Suppl) on (a) plasma $\beta$-alanine, (b) soleus carnosine and (c) gastrocnemius carnosine concentrations, analysed by a repeated-measures ANCOVA. Values are means and standard deviations represented by vertical bars. $\square$, Baseline (0 months; 0M); $\square, 3$ months; $\square, 6$ months. * $P<0.05$ compared with $\mathrm{OM}$.

Table 3. $\mathrm{VO}_{2 \max }$ and time to exhaustion (TTE) in an incremental cycling exercise test for the three experimental groups at baseline (0 months; $0 \mathrm{M})$, 3 months $(3 \mathrm{M})$ and 6 months $(6 \mathrm{M})$ analysed by a repeated-measures ANOVA

(Mean values and standard deviations)

\begin{tabular}{|c|c|c|c|c|c|c|}
\hline & \multicolumn{2}{|c|}{$\mathrm{OM}$} & \multicolumn{2}{|c|}{$3 \mathrm{M}$} & \multicolumn{2}{|c|}{$6 \mathrm{M}$} \\
\hline & Mean & SD & Mean & SD & Mean & $\mathrm{SD}$ \\
\hline \multicolumn{7}{|c|}{$\mathrm{VO}_{2 \max }(\mathrm{ml} / \mathrm{min}$ per $\mathrm{kg})$} \\
\hline Control & $40 \cdot 4$ & $6 \cdot 4$ & $39 \cdot 0$ & 8.8 & $39 \cdot 4$ & $6 \cdot 9$ \\
\hline Veg + Pla & $39 \cdot 4$ & $6 \cdot 4$ & $37 \cdot 8$ & $8 \cdot 0$ & $38 \cdot 1$ & $6 \cdot 6$ \\
\hline Veg + Suppl & $36 \cdot 6$ & $6 \cdot 3$ & $34 \cdot 8$ & $4 \cdot 7$ & 34.5 & 4.9 \\
\hline \multicolumn{7}{|l|}{ TTE (min) } \\
\hline Control & 14.5 & 1.9 & $14 \cdot 0$ & $3 \cdot 0$ & $14 \cdot 6$ & $2 \cdot 2$ \\
\hline $\mathrm{Veg}+\mathrm{Pla}$ & $15 \cdot 1$ & $2 \cdot 7$ & $14 \cdot 7$ & 2.5 & $15 \cdot 0$ & 2.5 \\
\hline Veg + Suppl & $13 \cdot 8$ & $2 \cdot 6$ & $13 \cdot 6$ & $2 \cdot 4$ & $13 \cdot 8$ & 2.9 \\
\hline
\end{tabular}

Veg + Pla, vegetarian + placebo; Veg + Suppl, vegetarian + supplemental creatine and $\beta$-alanine.

homeostasis was not affected. Further quantification of muscle carnosine content demonstrated that muscle carnosine homeostasis is also not affected after 6 months of vegetarianism. 
Table 4. Capillary lactate and $\mathrm{pH}$ at baseline (0 months; $0 \mathrm{M}), 3$ months $(3 \mathrm{M})$ and 6 months $(6 \mathrm{M})$ at rest and at the end of the incremental cycling test (Mean values and standard deviations)

\begin{tabular}{|c|c|c|c|c|c|c|c|c|c|c|c|c|}
\hline & \multicolumn{4}{|c|}{$\mathrm{OM}$} & \multicolumn{4}{|c|}{$3 \mathrm{M}$} & \multicolumn{4}{|c|}{$6 \mathrm{M}$} \\
\hline & \multicolumn{2}{|c|}{ Start } & \multicolumn{2}{|c|}{ End } & \multicolumn{2}{|c|}{ Start } & \multicolumn{2}{|c|}{ End } & \multicolumn{2}{|c|}{ Start } & \multicolumn{2}{|c|}{ End } \\
\hline & Mean & SD & Mean & SD & Mean & SD & Mean & SD & Mean & SD & Mean & SD \\
\hline \multicolumn{13}{|l|}{ Lactate $(\mathrm{mmol} / \mathrm{l})$} \\
\hline Control & 1.9 & 0.5 & 10.7 & 1.6 & $2 \cdot 4$ & 1.0 & $11 \cdot 4$ & 2.6 & $2 \cdot 0$ & 0.5 & $12 \cdot 1$ & $2 \cdot 0$ \\
\hline Veg + Pla & $2 \cdot 0$ & 0.7 & $12 \cdot 4$ & $4 \cdot 2$ & $2 \cdot 0$ & 0.9 & $14 \cdot 1$ & $2 \cdot 1$ & 1.7 & 0.4 & $12 \cdot 7$ & $1 \cdot 1$ \\
\hline Veg + Suppl & 1.8 & 0.8 & $10 \cdot 7$ & $2 \cdot 7$ & $2 \cdot 2$ & 0.9 & $12 \cdot 2$ & $2 \cdot 3$ & $2 \cdot 2$ & $1 \cdot 1$ & $13 \cdot 1$ & $2 \cdot 1$ \\
\hline \multicolumn{13}{|l|}{$\mathrm{pH}$} \\
\hline Control & 7.40 & 0.02 & $7 \cdot 28$ & 0.03 & 7.40 & 0.03 & $7 \cdot 27$ & 0.04 & 7.42 & 0.04 & $7 \cdot 29$ & 0.05 \\
\hline Veg + Pla & $7 \cdot 41$ & 0.02 & $7 \cdot 24$ & 0.07 & 7.42 & 0.03 & $7 \cdot 23$ & 0.04 & 7.43 & 0.02 & $7 \cdot 27$ & 0.03 \\
\hline Veg + Suppl & 7.42 & 0.02 & $7 \cdot 28$ & 0.06 & 7.41 & 0.01 & $7 \cdot 26$ & 0.04 & 7.43 & 0.01 & $7 \cdot 28$ & 0.04 \\
\hline
\end{tabular}

Veg + Pla, vegetarian + placebo; Veg + Suppl, vegetarian + supplemental creatine and $\beta$-alanine

Table 5. Daily intake of energy content, proteins, carbohydrates and fat through the regular diet both at the start (0 months; $0 \mathrm{M})$ and after 3 months (3M)(Mean values and standard deviations)

\begin{tabular}{|c|c|c|c|c|}
\hline & \multicolumn{2}{|c|}{$\mathrm{OM}$} & \multicolumn{2}{|c|}{$3 \mathrm{M}$} \\
\hline & Mean & SD & Mean & SD \\
\hline \multicolumn{5}{|c|}{ Energy $(\mathrm{kJ} / \mathrm{d})$} \\
\hline Control & 8690 & $1733 \cdot 0$ & 8615 & $1930 \cdot 1$ \\
\hline Veg & 9163 & $1444 \cdot 7$ & 9724 & $2675 \cdot 2$ \\
\hline \multicolumn{5}{|c|}{ Energy (kcal/d) } \\
\hline Control & 2077 & $414 \cdot 2$ & 2059 & $461 \cdot 3$ \\
\hline Veg & 2190 & $345 \cdot 3$ & 2324 & $639 \cdot 4$ \\
\hline \multicolumn{5}{|c|}{ Protein $(\mathrm{g} / \mathrm{d})$} \\
\hline Control & $75 \cdot 3$ & $17 \cdot 6$ & $70 \cdot 2$ & $20 \cdot 1$ \\
\hline Veg & 78.9 & $15 \cdot 4$ & $69 \cdot 7$ & $16 \cdot 1$ \\
\hline \multicolumn{5}{|c|}{ Carbohydrates $(\mathrm{g} / \mathrm{d})$} \\
\hline Control & $240 \cdot 7$ & $48 \cdot 3$ & $254 \cdot 2$ & $65 \cdot 3$ \\
\hline Veg & $243 \cdot 0$ & $41 \cdot 2$ & $282 \cdot 0$ & $83 \cdot 6$ \\
\hline \multicolumn{5}{|l|}{ Fat $(g / d)$} \\
\hline Control & $83 \cdot 0$ & $22 \cdot 8$ & 71.4 & $39 \cdot 7$ \\
\hline Veg & $87 \cdot 2$ & $22 \cdot 4$ & $94 \cdot 3$ & $37 \cdot 2$ \\
\hline
\end{tabular}

Veg, vegetarian subjects.

Unfortunately, no muscle creatine and carnitine data were available at this time point; however, plasma measurements suggest that carnitine homeostasis was also maintained at 6 months, whereas creatine homeostasis continued not to be. Total creatine is, alongside glycogen, the most abundant metabolite in human skeletal muscle with concentrations of about $120-150 \mathrm{mmol} / \mathrm{kg} \mathrm{dw}$. As previously mentioned, it is known to have a high turnover rate in comparison with carnitine and carnosine, with $1.7 \%$ of the total body creatine pool turned over per day. Consequently, in the women participating in this study, with a body pool of approximately $110 \mathrm{~g}$ of total creatine, approximately $1.6 \mathrm{~g} / \mathrm{d}$ has to be replaced by dietary creatine intake and de novo biosynthesis ${ }^{(22)}$. It has been demonstrated that in a diet containing meat and fish the average creatine intake is approximately $1.0 \mathrm{~g} / \mathrm{d}^{(37)}$ and $1-2 \mathrm{~g} / \mathrm{d}$ of creatine is endogenously synthesised from arginine, glycine and methionine in liver, kidney and pancreas ${ }^{(22)}$. Thus, in the case of a creatine-poor diet, approximately twice as much creatine needs to be endogenously synthesised to maintain the body creatine pool, which the current data demonstrate is not possible when omnivores switch to a vegetarian diet. When muscle creatine stores decline in response to a vegetarian diet, one would also expect urinary creatinine clearance to decline by a similar magnitude, as there is no enzymatic control for the hydrolysis of creatine and total muscle mass is assumed to remain stable. Muscle total creatine content declined by $14.6 \%$ (interaction effect $P=0.017$ ) in the Veg + Pla group at 3 months. Although the relative change in urinary creatinine was of the same magnitude $(-14.2 \%)$, this did not reach significance (interaction effect $P=0 \cdot 344$ ), which is most likely related to the higher inter-individual variability of the latter variable.

Carnitine and carnosine have a lower muscular concentration (20-30 mmol/ $\mathrm{kg} \mathrm{dw}$ ) and a much slower turnover rate than creatine. Healthy subjects excrete carnitine at a rate of approximately $5 \mu \mathrm{mol} / \mathrm{kg} / \mathrm{d}$, which, for the women participating in this study, amounts to $\sim 315 \mu \mathrm{mol} / \mathrm{d}$ (corresponding to approximately $0.05 \mathrm{~g} / \mathrm{d}$ and $0.02 \%$ of total body carnitine pool) ${ }^{(6)}$. For muscle carnosine, washout time after a period of carnosine loading by $\beta$-alanine supplementation was shown to be a slow process that takes $6-20$ weeks $^{(23)}$, demonstrating the slow degradation rate of carnosine. Baguet et al. ${ }^{(23)}$ calculated that, in absolute terms, the elimination of carnosine is about $0.5 \mathrm{~g} / \mathrm{d}$, which corresponds to approximately $0.15 \%$ of total body carnosine pool and is thus 10-fold slower than that for creatine $(1.7 \%)$.

To our knowledge, this is the first long-term intervention study demonstrating that body creatine stores decline after initiation of a vegetarian diet. Our results are in accordance with cross-sectional data on plasma and urinary creatine and creatinine values in vegetarian subjects ${ }^{(16)}$. Muscle total creatine decreased within 3 months by $14 \%$ in our subjects, which is in accordance with the cross-sectional decrease $(-10 \%)$ in muscle total creatine found in the study of Burke et $a l^{(19)}$ and the longitudinal decrease $(-10 \%)$ after a 3-week intervention period in omnivorous subjects ${ }^{(24)}$. However, this decrease did not affect $\mathrm{VO}_{2 \max }$ nor TTE of the incremental cycling test. Although the exercise modes were much different in nature, this is in accordance with previous studies that did not find a difference between vegetarian and non-vegetarian subjects for exercise performance measures, such as 320 -s bouts of maximal cycling ${ }^{(38)}$ and 1-repetition maximum bench press and 
leg press ${ }^{(19)}$. However, reduced muscle total creatine levels might affect other short-term high-intensity performances such as sprinting, in which phosphocreatine plays a key role.

Interestingly, low-dose creatine supplementation combined with a vegetarian diet was able to maintain muscle total creatine content at baseline levels after 3 months and even triple plasma creatine concentrations at 6 months, thereby making creatine a valid supplement for vegetarian athletes participating in high-intensity exercises. A daily dose of $1 \mathrm{~g}$ of creatine monohydrate seems to be a sufficient dose to prevent deficiencies, which is considerably lower than the $3-20 \mathrm{~g} / \mathrm{d}$ required to elevate muscle creatine stores above the baseline set point ${ }^{(39)}$. As the daily ingestion of $0.88 \mathrm{~g}$ creatine $(1 \mathrm{~g}$ creatine monohydrate) is adequate to avoid a decline in body creatine stores on the background of a creatine-free vegetarian diet, the remainder of the daily creatine requirement is probably met by endogenous synthesis in kidney and liver.

Carnitine homeostasis of either plasma or muscle was not influenced by initiation of a vegetarian diet. Dietary carnitine intake is mainly attributable to the intake of meat and fish (animal source), although it is not completely absent in dairy products and some vegetables, fruit and cereals ${ }^{(40)}$. Thus, carnitine is also present in moderate amounts in a vegetarian diet and has a slow turnover rate relative to that of creatine, which is in line with the absence of an effect of 6 months vegetarianism on plasma carnitine concentrations, as we hypothesised. As all experimental groups display the same pattern in the current study, namely lower carnitine and acetylcarnitine concentrations at $3 \mathrm{M}$, which seemed to be restored at $6 \mathrm{M}$, this could have reflected seasonal variations rather than effects of the intervention. The study was initiated in mid-December and the intermediate measurements were performed in March; thus, the first half of the intervention period was during winter, whereas the second part, with the final measurements in the second half of June, was during spring. Therefore, we hypothesised that vitamin D status may be an underlying mechanism for the observed seasonal fluctuations in carnitine homeostasis. This hypothesis was based on the findings of Dursun ${ }^{(41)}$ who found decreased plasma carnitine levels and increased carnitinuria in severe vitamin D deficiency patients (rickets), and rodent studies ${ }^{(42)}$ have documented that low vitamin D status impairs lipid oxidation capacity, including carnitine palmitoyltransferase-1 expression. Our results indicate that, similar to carnitine, seasonal fluctuations are found in serum vitamin D concentration on group level. Yet, when looking at individual level, a significant negative correlation between serum vitamin D and plasma total carnitine content was found, which would indicate that vitamin D cannot explain the seasonal fluctuations in carnitine homeostasis in the present study. The discrepancy with previous literature ${ }^{(41,42)}$ probably relates to the severity of vitamin D deficiency in the latter studies, as compared with the physiological range in the present study.

Published cross-sectional data showed lower plasma carnitine concentrations in vegetarians than in omnivores ${ }^{(15-18)}$, which is in contrast to our present data. However, this is probably explained by difference in the duration of vegetarianism (1.5-20 years $v$. 6 months the present study). It is hypothesised that renal conservation mechanisms and thus higher carnitine reabsorption may occur in vegetarians to compensate for the lower carnitine concentrations obtained from the diet, thereby keeping plasma carnitine concentrations within a relatively normal range ${ }^{(17,43)}$. Furthermore, some inconsistency exists also regarding muscle carnitine content, as Novakova et $a l .{ }^{(15)}$ did not find a lower muscle content in vegetarians compared with omnivores, whereas Stephens et $a l^{(18)}$ reported a $17 \%$ difference. However, it should be noted that the study of Novakova et $a l^{(15)}$ included only male vegetarians who consumed a vegetarian diet for at least 1.5 years, whereas the study of Stephens et al. ${ }^{(18)}$ included both male and female subjects who are vegetarians for 11 years on average. It can be concluded that seasonal variation may have a greater impact on body carnitine homeostasis than a change to vegetarian dietary habits in the short-term; however, long-lasting vegetarianism ( $>1.5$ years) is likely to have a bigger impact.

Given that $\beta$-alanine is the rate-limiting precursor for carnosine synthesis in human muscle cells and vegetarian diets are free of $\beta$-alanine and carnosine (including its methylated variants anserine and balenine), it is somewhat surprising that muscle carnosine content was unaltered after a 6-month vegetarian diet in previously omnivorous subjects. This suggests that maintenance of carnosine homeostasis does not depend on the nutritional supply of $\beta$-alanine. Thus, endogenous $\beta$-alanine synthesis can probably entirely compensate for the absence of dietary $\beta$-alanine and thereby maintain body homeostasis, at least during the 1st months of vegetarianism. Current findings on muscle carnosine content are somewhat in contrast with cross-sectional data on long-term vegetarians (>7years) reported in the study of Everaert et $a l^{(20)}$ and preliminary report of Harris et $a l .{ }^{(21)}$. However, it should be noted that in the study of Everaert et $a l .{ }^{(20)}$, although the lower muscle carnosine content in vegetarians ( $n$ 12) $v$. omnivores $(n 38)$ reached significance in the gastrocnemius, this was not the case for soleus and tibialis anterior muscles. Furthermore, the report of Harris et $a l^{(21)}$ included only six vegetarians and was not sex- and age-matched (which is important for carnosine ${ }^{(28)}$ ).

Interestingly, low dose of $\beta$-alanine supplementation $(0 \cdot 8 \mathrm{~g} / \mathrm{d})$ for 3 months in vegetarians significantly increased plasma $\beta$-alanine and muscle carnosine content by $20-30 \%$. Knowing that the average daily intake of $\beta$-alanine from an omnivore Western diet has been calculated to amount to approximately $330 \mathrm{mg} / \mathrm{d}^{(20)}$, the daily intake of an additional approximately $500 \mathrm{mg} / \mathrm{d}$, which corresponds to a total ingested dose of approximately $46 \mathrm{~g}$ in 3 months, is responsible for this increase. Because of the increase in carnosine above baseline concentration with this initial dose $(0.8 \mathrm{~g} / \mathrm{d}), \beta$-alanine dose was reduced to $0.4 \mathrm{~g} / \mathrm{d}$ during the last 3 months of the study. This dose did not further enhance plasma $\beta$-alanine and muscle carnosine concentrations, neither did it restore these concentrations to baseline, suggesting that this dose was still higher than the normal dietary $\beta$-alanine intake of these subjects. However, in contrast to previous research ${ }^{(27)}$, no effect of $\beta$-alanine supplementation was found on TTE of the incremental cycling test. This is most likely owing to the different dosing strategy of $\beta$-alanine (up to $6.4 \mathrm{~g} / \mathrm{d}^{(27)} v \cdot 0.8$ and $0.4 \mathrm{~g} / \mathrm{d}$ in current study) and consequently different effects on muscle carnosine. 
Some urinary biomarkers of meat intake are known, such as pi-methylhistidine, tau-methylhistidine and anserine ${ }^{(44-46)}$. A clear reduction in urinary excretion of these compounds, for pi-methylhistidine to an order of magnitude lower than the original value, was observed in the vegetarian subjects, proving that they complied with the vegetarian intervention. A limitation of the current study is that data of the muscle biopsies at $6 \mathrm{M}$ are missing, making it impossible to draw conclusions on the effect of a 6-month vegetarian diet on intramuscular creatine and carnitine concentrations.

It can be concluded that changing to a vegetarian diet reduces the body creatine pool in omnivorous women after 3 months, which can be avoided by dietary creatine supplementation. This points to creatine being a suitable supplement for vegetarian athletes, especially those participating in resistance training and short-term, high-intensity exercise performance. Carnitine homeostasis was not disrupted by switching to a 3-month vegetarian diet, and carnosine homeostasis was unaffected by a 6-month vegetarian diet. This suggests that for carnitine and carnosine, which have a comparatively lower turnover rate than creatine, endogenous synthesis can maintain homeostasis for at least 3 to 6 months, respectively.

\section{Acknowledgements}

This study was financially supported by grants from the Research Foundation - Flanders (FWO G.0243.11 and G.0352.13N).

The authors' responsibilities were as follows: L. B., A. B., T. B., I. E., S. D. H. and W. D. designed the research and formulated the research question; L. B., A. B., T. B., I. E., A. V., M. P., C. V., S. D. H. and W. D. conducted and supervised the study intervention; L. B., A. B., T. B., A. V., I. E., J. D., D. C.-T., P. G. and W. D. performed data analysis and statistical analysis; L. B., A. B., P. G. and W. D. wrote the paper; and W. D. had primary responsibility for final content. He is the guarantor of this work, and, as such, had full access to all the data in the study and takes responsibility for the integrity of the data and the accuracy of the data analysis. All authors provided intellectual input for the manuscript and read and approved the final manuscript.

Creatine supplements were kindly provided by Dr Ulrike Braun from AlzChem (Trostberg, Germany) and $\beta$-alanine supplements were provided by Dr Roger Harris and Dr Zimin Liu from Natural Alternatives International (NAI, San Marcos, USA). The authors declare that there are no conflicts of interest.

\section{References}

1. Tantamango-Bartley Y, Jaceldo-Siegl K, Fan J, et al. (2013) Vegetarian diets and the incidence of cancer in a low-risk population. Cancer Epidemiol Biomarkers Prev 22, 286-294.

2. McEvoy CT, Temple N \& Woodside JV (2012) Vegetarian diets, low-meat diets and health: a review. Public Health Nutr 15, 2287-2294.

3. Orlich MJ, Singh PN, Sabaté J, et al. (2013) Vegetarian dietary patterns and mortality in Adventist Health Study 2. JAMA Intern Med 173, 1230-1238.

4. Leitzmann C (2005) Vegetarian diets: what are the advantages? Forum Nutr 57, 147-156.
5. Gualano B, Rawson ES, Candow DG, et al. (2016) Creatine supplementation in the aging population: effects on skeletal muscle, bone and brain. Amino Acids $\mathbf{4 8}$, 1793-1805.

6. Steiber A, Kerner J \& Hoppel CL (2004) Carnitine: a nutritional, biosynthetic, and functional perspective. Mol Aspects Med 25, 455-473.

7. Fritz IB \& Marquis NR (1965) The role of acylcarnitine esters and carnitine palmityltransferase in the transport of fatty acyl groups across mitochondrial membranes. Proc Natl Acad Sci U S A 54, 1226-1233.

8. Seiler S, Koves T, Gooding J, et al. (2015) Carnitine acetyltransferase mitigates metabolic inertia and muscle fatigue during exercise. Cell Metab 22, 65-76.

9. Blancquaert L, Everaert I \& Derave W (2015) Beta-alanine supplementation, muscle carnosine and exercise performance. Curr Opin Clin Nutr Metab Care 18, 63-70.

10. Hobson RM, Saunders B, Ball G, et al. (2012) Effects of $\beta$-alanine supplementation on exercise performance: a metaanalysis. Amino Acids 43, 25-37.

11. Wall BT, Stephens FB, Constantin-Teodosiu D, et al. (2011) Chronic oral ingestion of L-carnitine and carbohydrate increases muscle carnitine content and alters muscle fuel metabolism during exercise in humans. J Physiol J Physiol J Physiol 5894, 963-973.

12. Twycross-Lewis R, Kilduff LP, Wang G, et al. (2016) The effects of creatine supplementation on thermoregulation and physical (cognitive) performance: a review and future prospects. Amino Acids 48, 1843-1855.

13. Boldyrev AA, Aldini G \& Derave W (2013) Physiology and pathophysiology of carnosine. Physiol Rev 93, 1803-1845.

14. Pinto CL, Botelho PB, Pimentel GD, et al. (2016) Creatine supplementation and glycemic control: a systematic review. Amino Acids 48, 2103-2129.

15. Novakova K, Kummer O, Bouitbir J, et al. (2016) Effect of l-carnitine supplementation on the body carnitine pool, skeletal muscle energy metabolism and physical performance in male vegetarians. Eur J Nutr 55, 207-217.

16. Delanghe J, De Slypere J-P, De Buyzere M, et al. (1989) Normal reference values for creatine, creatinine, and carnitine are lower in vegetarians. Clin Chem 35, 1988-1989.

17. Lombard KA, Olson L, Nelson SE, et al. (1989) Carnitine status of lactoovovegetarians and strict vegetarian adults and children. Am J Clin Nutr 50, 301-306.

18. Stephens FB, Marimuthu K, Cheng Y, et al. (2011) Vegetarians have a reduced skeletal muscle carnitine transport capacity. Am J Clin Nutr 94, 938-944.

19. Burke DG, Chilibeck PD, Parise G, et al. (2003) Effect of creatine and weight training on muscle creatine and performance in vegetarians. Med Sci Sports Exerc 35, 1946-1955.

20. Everaert I, Mooyaart A, Baguet A, et al. (2011) Vegetarianism, female gender and increasing age, but not CNDP1 genotype, are associated with reduced muscle carnosine levels in humans. Amino Acids 40, 1221-1229.

21. Harris RC, Jones G, Hill C, et al. (2007) The carnosine content of vastus lateralis in vegetarians and omnivores. FASEB J 21, A944.

22. Wyss M \& Kaddurah-Daouk R (2000) Creatine and creatinine metabolism. Physiol Rev 80, 1107-1213.

23. Baguet A, Reyngoudt H, Pottier A, et al. (2009) Carnosine loading and washout in human skeletal muscles. I Appl Physiol 106, 837-842.

24. Lukaszuk JM, Robertson RJ, Arch JE, et al. (2002) Effect of creatine supplementation and a lacto-ovo-vegetarian diet on muscle creatine concentration. Int J Sport Nutr Exerc Metab 12, 336-348. 
25. Baguet A, Everaert I, De Naeyer H, et al. (2011) Effects of sprint training combined with vegetarian or mixed diet on muscle carnosine content and buffering capacity. Eur J Appl Physiol 111, 2571-2580.

26. Nelson AG, Day R, Glickman-Weiss EL, et al. (2000) Creatine supplementation alters the response to a graded cycle ergometer test. Eur J Appl Physiol 83, 89-94.

27. Stout JR, Cramer JT, Zoeller RF, et al. (2007) Effects of beta-alanine supplementation on the onset of neuromuscular fatigue and ventilatory threshold in women. Amino Acids $\mathbf{3 2}$, 381-386.

28. Baguet A, Everaert I, Achten E, et al. (2012) The influence of sex, age and heritability on human skeletal muscle carnosine content. Amino Acids 43, 13-20.

29. Kreider RB, Kalman DS, Antonio J, et al. (2017) International Society of Sports Nutrition position stand: safety and efficacy of creatine supplementation in exercise, sport, and medicine. J Int Soc Sports Nutr 14, 18.

30. Décombaz J, Beaumont M, Vuichoud J, et al. (2012) Effect of slow-release $\beta$-alanine tablets on absorption kinetics and paresthesia. Amino Acids 43, 67-76.

31. Green AL, Hultman E, Macdonald IA, et al. (1996) Carbohydrate ingestion augments skeletal muscle creatine accumulation during creatine supplementation in humans. Am J Physiol 271, E821-E826.

32. Stegen S, Blancquaert L, Everaert I, et al. (2013) Meal and beta-alanine coingestion enhances muscle carnosine loading. Med Sci Sports Exerc 45, 1478-1485.

33. Cognat S, Cheillan D, Piraud M, et al. (2004) Determination of guanidinoacetate and creatine in urine and plasma by liquid chromatography-tandem mass spectrometry. Clin Chem 50, 1459-1461.

34. Harris R, Hultman E \& Nordesjö L (1974) Glycogen, glycolytic intermediates and high-energy phosphates determined in biopsy samples of musculus quadriceps femoris of man at rest. Methods and variance of values. Scand J Clin Lab Invest 33, 109-120.
35. Cederblad G, Carlin JI, Constantin-Teodosiu D, et al. (1990) Radioisotopic assays of COASH and carnitine and their acetylated forms in human skeletal muscle. Anal Biochem 185, 274-278.

36. Baguet A, Bourgois J, Vanhee L, et al. (2010) Important role of muscle carnosine in rowing performance. J Appl Physiol 109, 1096-1101.

37. Balsom PD, Söderlund K \& Ekblom B (1994) Creatine in humans with special reference to creatine supplementation. Sport Med 18, 268-280.

38. Shomrat A, Weinstein Y \& Katz A (2000) Effect of creatine feeding on maximal exercise performance in vegetarians. Eur J Appl Physiol 82, 321-325.

39. Hultman E, Söderlund K, Timmons JA, et al. (1996) Muscle creatine loading in men. J Appl Physiol 81, 232-237.

40. Krajčovičová-Kudláčková $\mathrm{M}$, Šimončič $\mathrm{R}$, Béderová A, et al. (2000) Correlation of carnitine levels to methionine and lysine intake. Physiol Res 49, 399-402.

41. Dursun A (2000) Carnitinuria in rickets due to vitamin D deficiency. Turk J Pediatr 42, 278-280.

42. Park S, Kim DS \& Kang S (2016) Vitamin D deficiency impairs glucose-stimulated insulin secretion and increases insulin resistance by reducing PPAR-y expression in nonobese type 2 diabetic rats. J Nutr Biochem 27, 257-265.

43. Rebouche J, Lombard A \& Chenard A (1993) Renal adaptation to dietary carnitine in humans. Am J Clin Nutr 58, 660-665.

44. Cross AJ, Major JM \& Sinha R (2011) Urinary biomarkers of meat consumption. Cancer Epidemiol Biomarkers Prev 20, 1107-1111

45. Dragsted LO (2010) Biomarkers of meat intake and the application of nutrigenomics. Meat Sci 84, 301-307.

46. Altorf-van der Kuil W, Brink EJ, Boetje M, et al. (2013) Identification of biomarkers for intake of protein from meat, dairy products and grains: a controlled dietary intervention study. Br J Nutr 110, 810-822. 